\title{
Research on Fault Location Method of VSWR for GSM-R System Leaky Cable
}

\author{
GuoJinxi $^{\mathrm{a}}$, Liu Yang ${ }^{\mathrm{b}}$, Li Duan ${ }^{\mathrm{c}}$, Han Xiucao ${ }^{\mathrm{d}}$ \\ School of Mechanical Electrical and Information Engineering, China University of Mining and \\ Technology (Beijing), Beijing, 100083; \\ agjinxi2009@163.com, ${ }^{b}$ liuyangebox@126.com, ${ }^{\mathrm{c}} 120628455 @ q q . c o m,{ }^{\mathrm{d}} 280050459 @ q q . c o m$
}

Key words: GSM-R; leaky coaxial cable; VSWR; fault location

\begin{abstract}
The security and stability of GSM-R wireless communication system plays an important role in the maintenance of railway operation. According to the GSM-R system, this paper gives the system composition of GSM-R, calculates the transmission loss of leaky coaxial cable and analyzes the common faults of leaky coaxial cable. This paper analyzes the principle of the VSWR method, and the steps of the method in the testing process and the matters needing attention in the implementation.
\end{abstract}

\section{Introduction}

With the expansion of the national high-speed rail network, high-speed rail operating mileage has accounted for more than $60 \%$ of the global high-speed rail operations, running speed of 300 kilometers per hour. The comprehensive inspection department of the Ministry of Railways check the running state of the high-speed railway, including the track, pantograph, GSM-R network and signal system. GSM-R(Global System for Mobile Communications - Railway) network can expand the coverage of the base station, especially the application of leaky coaxial cable (leaky coaxial cable) can the maximum to eliminate the blind zone of the tunnel ${ }^{[1]}$.The communication quality of network state and signal system of GSM-R has great influence on the operation of high speed railway control system. The leaky coaxial cable in the tunnel will be locked and reinforced by rivet every meter. Due to the installation of construction or engineering, part of the leaky coaxial cable connected joint, jumper, DC-Block, antenna will begin to enter the fault prone period. But because of the practical difficulties of maintenance, such as tunnel and time window constraints, one by one investigation by artificial will be difficult to detect and locate the fault, this paper uses the method in VSWR measurement for detection and fault location of the leaky cable in GSM-R system.

\section{Schematic Diagram Of GSM-R Link}

The uplink frequency of GSM-R mobile communication system in China's high-speed railway applications is $885 \mathrm{MHz}-889 \mathrm{MHz}$, the downlink frequency is $930 \mathrm{MHz}-934 \mathrm{MHz}$. The link diagram of GSM-R system ${ }^{[2]}$ is shown in Figure 1.

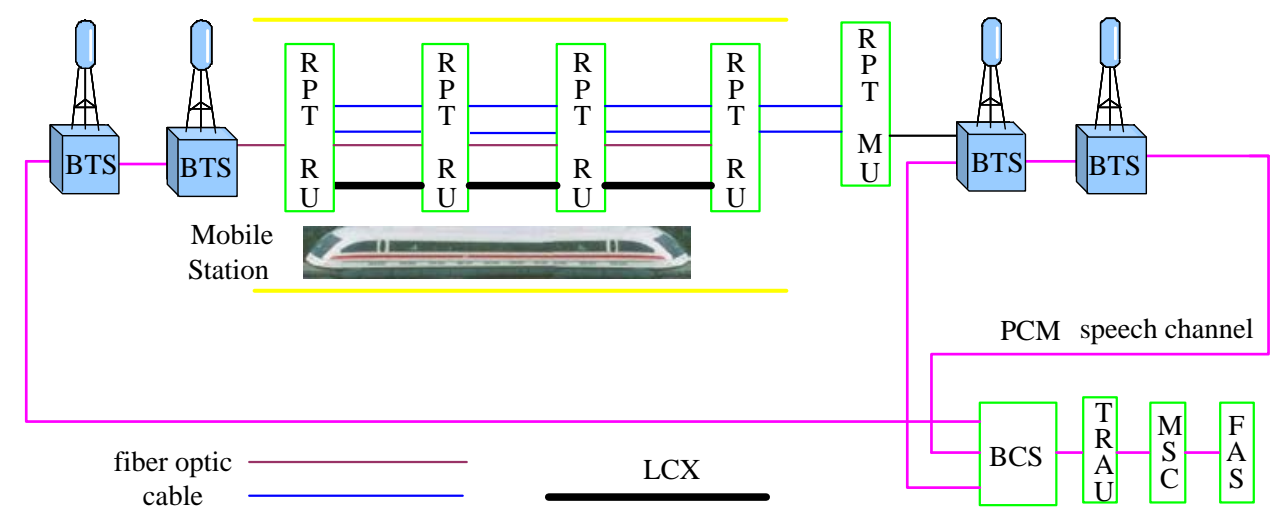

Fig.1 The link diagram of GSM-R system 
Station FAS dispatching system and mobile switching center (MSC) are connected, the mobile switching center provides call processing functions and mobile specific features, the compilation code and Transcoding and Rate Adaptation Unit (TRAU)connect the user data stream to a receiver modem device with a communication function. TRAU is connected to the base station control system (BCS) through the alter interface. BTS is responsible for the reception and transmission of mobile signals, laying at both ends of the tunnel. At the entrance of the tunnel, communication signals are coupled via power divider by using of RU and then are transmitted to MU, the remote machine will radiate RF signal to tunnel space through the leaky coaxial cable.

\section{Calculation Of Transmission Loss Of Leaky Cable}

In the transmission process of the leaky coaxial cable, the signal is radiated through the slot of leakage cable, causing internal signal energy attenuation. Besides, there is also a conductor loss and dielectric loss.The formula for the transmission loss of the leaky cable is ${ }^{[3]}$ :

$$
\alpha=\alpha_{c}+\alpha_{d}+\alpha_{r}
$$

$\alpha$ - the transmission loss of the leaky cable;

$\alpha_{c}$-the conductor loss of leaky cable;

$\alpha_{d}$ - the dielectric loss of leaky cable;

$\alpha_{r}$ - the radiation loss of leaky cable;

Signal attenuation of leaky cable means that the quality of the wireless signal, fault cable leakage will cause the transmission loss and abnormal radiation signal, which has important influence on the stability of the wireless communication, and is also the hidden trouble of the railway communication. The method used in the current railway department is to use the field strength meter to measure the radio field strength of the leaky cable line every month. Then according to the normal value of the attenuation of each device, we can calculate the normal attenuation of each section of leaky coaxial cable. By comparison, we can know whether the attenuation of leaky cable is normal. The attenuation of the various components of the values is shown in table 1.

Tab.1 The standard attenuation value of leaky coaxial cable and device

\begin{tabular}{cccccccc}
\hline $\begin{array}{c}\text { leaky } \\
\text { coaxial } \\
\text { cable and } \\
\text { device }\end{array}$ & $\begin{array}{c}\text { leaky } \\
\text { coaxial } \\
\text { cable } \\
(\mathrm{dB} / 100 \\
\text { meters })\end{array}$ & $\begin{array}{c}1 / 2 \\
\text { feeder } \\
(\mathrm{dB} / 100 \\
\text { meters })\end{array}$ & $\begin{array}{c}\text { feeder } \\
(\mathrm{dB} / 100 \\
\text { meters })\end{array}$ & $\begin{array}{c}13 / 8 \\
\text { feeder } \\
(\mathrm{dB} / 100 \\
\text { meters })\end{array}$ & $\begin{array}{c}\text { power } \\
\text { divider } \\
(\mathrm{dB})\end{array}$ & $\begin{array}{c}\text { coupler } \\
(\mathrm{dB})\end{array}$ & $\begin{array}{c}\text { joint } \\
(\mathrm{dB})\end{array}$ \\
\hline $\begin{array}{c}\text { The } \\
\text { standard } \\
\text { attenuation } \\
\text { value }\end{array}$ & 2.3 & 6.9 & 3.5 & 2.4 & 3 & 1 & 0.1 \\
\hline
\end{tabular}

The sketch map of the situation of a section of a road section is shown in figure 2. The road is composed of 500 meters, 10 meters 1/2 cable, 90 meters 7/8 cable, a power divider, four lightning rod and 14 connectors. The values of theoretical calculation of attenuation section: $5 \times 2.3+0.1 \times 6.9+0.9 \times 3.5+1 \times 3+4 \times 0.1+14 \times 0.1=20.14 \mathrm{~dB}$; If the actual measured value and the theoretical calculation have a large deviation, it shows that the line has a fault. 


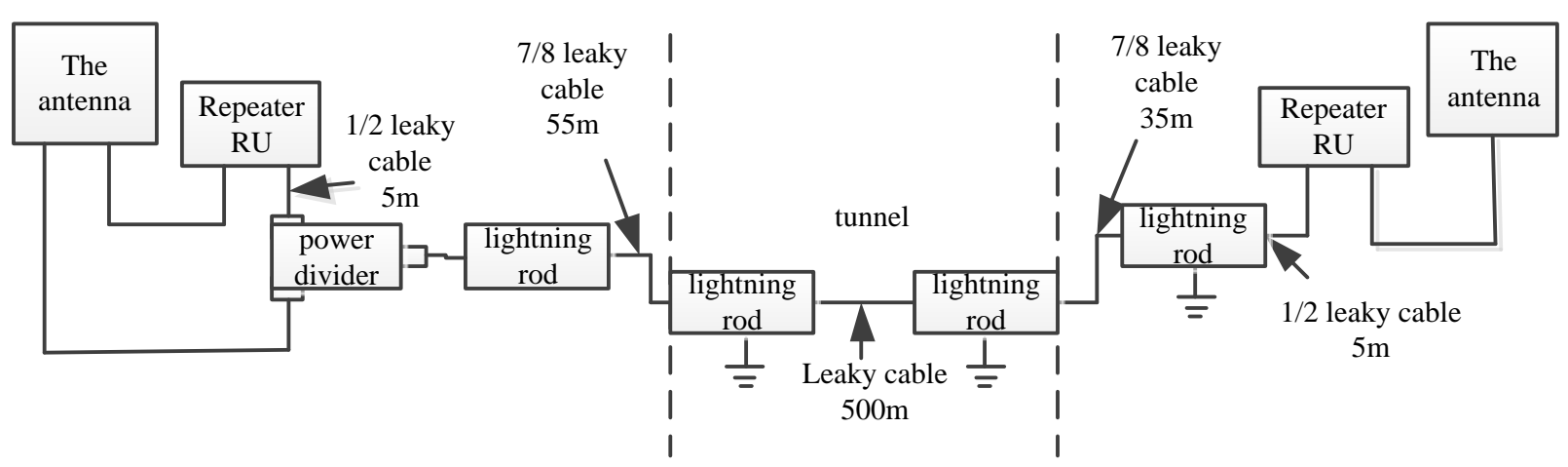

Fig.2 The situation of a section radiation diagram

\section{VSWR Method}

The principle of $\mathrm{VSWR}^{[4]}$ is the same as the principle of optical time domain reflection(OTDR), that is transmitting RF signal of a certain power, and then according to the characteristics of signal transmission cable leakage, local in homogeneity of conductor media and leaky cable fault in the leaky cable can generate back to Rayleigh scattering, and a part of the signal is scattered back to the detector. The full name of VSWR is voltage standing wave ratio, which is calculated by the reflection coefficient $\Gamma$. The formula of VSWR is:

$$
\mathrm{V}_{\mathrm{SWR}}=\frac{1+|\Gamma|}{1-|\Gamma|}
$$

Reflection coefficient $\Gamma=\frac{\mathrm{V}_{\mathrm{REV}}}{\mathrm{V}_{\mathrm{FWD}}}=\sqrt{\frac{\mathrm{P}_{\mathrm{REV}}}{\mathrm{P}_{\mathrm{FWD}}}}, \mathrm{V}_{\mathrm{REV}}, \mathrm{V}_{\mathrm{FWD}}$ are the incident signal voltage and the reflected signal voltage. $\mathrm{P}_{\mathrm{REV}}, \mathrm{P}_{\mathrm{FWD}}$ are the incident average power and reflected average power in a period of time.

In practical application, it is not by collecting the incident voltage $V_{\mathrm{REV}}$ and the reflected voltage $V_{F W D}$ to carry out the calculation of the VSWR, but using the equivalent return loss $R_{L}$ to represent the monitoring point of the incident power and reflection power ratio, $\mathrm{R}_{\mathrm{L}}$ 's expression is:

$$
\mathrm{R}_{\mathrm{L}}=10 \lg \frac{\mathrm{P}_{\mathrm{REV}}}{\mathrm{P}_{\mathrm{FWD}}}
$$

The relationship between return loss and reflection coefficient is

$$
\mathrm{R}_{\mathrm{L}}=-20 \log \left[\frac{\mathrm{V}_{\mathrm{SWR}}-1}{\mathrm{~V}_{\mathrm{SWR}}+1}\right]=-20 \log \Gamma
$$

Then there is $\Gamma=10^{-\frac{R_{L}}{20}}$. The reflection coefficient $\Gamma$ is 0 , and the VSWR is 1 under ideal conditions. In practice, due to the uneven conductor medium, the resistivity of the conductor changes. There is a reflection. VSWR is always greater than 1 .

\section{Fault Detection And Fault Location}

The bigger the VSWR, the greater the signal reflect back. At this time there is no matching load, which is the phenomenon of fault ${ }^{[5]}$. The relationship between $V S W R$ and reflectivity is shown in table 2.

Tab.2 The corresponding relation of SWR and reflectivity

\begin{tabular}{lllllllllll}
\hline SWR & 1.0 & 1.1 & 1.2 & 1.3 & 1.5 & 1.7 & 1.8 & 2.0 & 2.5 & 3.0 \\
\hline reflectivity & $0.00 \%$ & $0.23 \%$ & $0.83 \%$ & $1.70 \%$ & $4.00 \%$ & $6.72 \%$ & $8.16 \%$ & $11.11 \%$ & $18.37 \%$ & $25.00 \%$ \\
\hline
\end{tabular}

As shown in Figure 3, the time required to return the probe signal to the detector is t. The time signal transmission distance is 2L. P1 is the power of the transmit signal. P2, P3 is the incident power and reflection power of the fault point. P4 is the power to return to the transmitter. The 
attenuation of the unit length of the leaky cable is set up by $\lambda$. Let $\mathrm{K}$ for mismatch loss. By $\mathrm{P} 2=\mathrm{P} 1-\Lambda 1, \mathrm{~K}=\mathrm{P} 3-\mathrm{P} 2$ and $\mathrm{P} 4=\mathrm{P} 3-\lambda \mathrm{L}$, we get

Then there is

$$
\mathrm{K}=2 \lambda \mathrm{L}+(\mathrm{P} 4-\mathrm{P} 1)
$$

$$
2 L=v t
$$

$v$ is the transmission speed of the radio frequency signal in the leaky cable, Generally taking 0.8 times the speed of light.

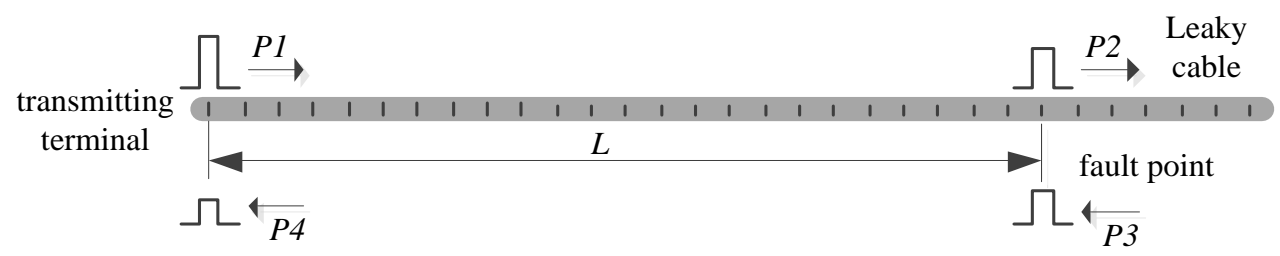

Fig.3 Fault test schematic diagram

When the measurement of VSWR is greater than the set value (set to 1.5), the fault location mode will be selected to carry out specific fault location. If the length of the cable is longer, the transmission loss will increase, the return signal is smaller and VSWR will be very small, which needs to be measured, which needs to be judged according to the length of the measured cable. In the detection of the leakage cable, adopting the method of sectioning VSWR tester. Concrete steps are as follows:

(1) Open the tunnel mouth and connect the $1 / 2$ feeder to the leaky cable.

(2)Drain the repeater equipment disconnect the cable and the tunnel, to ensure no leaky of RF signal cable.

(3)Using the VSWR test instrument in the tunnel entrance or tunnel repeater to test voltage VSWR. According to the measurement resolution, determining the measurement range, As shown in table 2 :

Tab.2 Measuring point and measuring distance table

\begin{tabular}{cccc}
\hline Test data points & $\begin{array}{c}\text { Measurement } \\
\text { resolution }(\mathrm{m})\end{array}$ & $\begin{array}{c}\text { Measuring } \\
\text { frequency } \\
\text { band(MHZ) }\end{array}$ & $\begin{array}{c}\text { Maximum } \\
\text { measuring } \\
\text { distance(m) }\end{array}$ \\
\hline 130 & 1.89 & $950-880=70$ & 245.7 \\
\hline 260 & 1.89 & $950-880=70$ & 491.4 \\
\hline 520 & 1.89 & $950-880=70$ & 982.8 \\
\hline
\end{tabular}

(4)Using S311D to measure the leaky cable VSWR. Meter use step: Select the VSWR test project: $\mathrm{MODE} \rightarrow$ FREQ-SWR $\rightarrow$ ENTER; Set test band: FREQ/DIST $\rightarrow$ F1 $\rightarrow$ Input start frequency $\rightarrow$ ENTER $\rightarrow$ F2 $\rightarrow$ Input termination frequency $\rightarrow$ ENTER(Ascending frequency 885 889 MHz, Downlink Frequency 930 934 MHz); Set frequency scan measurement points: MEASUREMENT/ SWEEP $\rightarrow$ RESOLUTION; Instrument calibration: Connect automatic calibration, press START CAL key(key 3, curve settings and data input keypad, the right panel), then press ENTER key to start calibration, CAL ON in the upper left corner of the display indicates the calibration has been completed and started.

Take off the automatic calibration, and connect the metering ports to the leak cable port, then press AUTO SCALE key, get measured curve. Press MARKER tags measurement of the key data points on the curve, continue to press the "edit" soft key. Read the frequency of the data points to the ENTER key. Storage measurement curve, according to SAVE the DISPLAY key ENTER name for the folder, press ENTER key.

The voltage VSWR measuring value is less than 1.5. For the fault point of VSWR more than 1.5, measure the fault location. Operating steps (curve amplitude higher position for a possible failure point): press MODE key, press up and down arrow keys to select screen, fault location - standing 
wave ratio, press ENTER. Press FREQ/DIST, according to the soft menu selection D1, type in the original position that needs to be measured, selectthe D2 to type itstermination position. Press the soft menu key, use the up and down arrow keys to select the parameters, such as the loss of the cable, etc. (can choose the cable type setting).

(1)In order to accurately locate the fault point, the 4 steps can be repeated.

(2)After the failure point is determined and the processing is completed, the network management of the repeater is contacted to confirm whether the leakage cable is restored.

\section{Acknowledgement}

In this paper, the research was sponsored by the National Nature Science Foundation of China (Project No. 51604279)

\section{References}

[1] Dai Zheng-hang, Yin Tong. Application of GSM-R feeder leaky cable for on-line monitoring system in high speed railway [J], RailwaySignalling\& Communication, 2014.50(9):77-79.

[2] SONGYang.Research on the Application and Realization of Real-time Monitoring System for Railway Communication of Leaky Coaxial Cable[J], Railwaystandarddesign, 2016.60(7): 150-153.

[3] He chen. Research on transmission loss and coupling loss of the leaky coaxial cable [D], University of Electronic Science and Technology of China, 2011,6

[4] Zhongbao Wang, Shaojun Fang, Shiqiang Fu. Broadband Stacked Patch Antenna with Low VSWR and Low Cross-Polarization[J]. ETRI Journal, 2010, 32(4).

[5] An Bo. The techniques of the VSWR test distance and fault location on the coaxial cable [J], Modern Transmission, 2008,5:53-55 